Check for updates

Cite this: RSC Adv., 2018, 8, 38808

\title{
Investigation of electrolytic flocculation for microalga Scenedesmus sp. using aluminum and graphite electrodes
}

\begin{abstract}
Shihong Liu, (D) *a Husam A. Abu Hajar, ${ }^{\text {b }}$ Guy Riefler ${ }^{c}$ and Ben J. Stuart (iD) ${ }^{d}$
Electrolytic flocculation using non-sacrificial electrodes with flocculants added was studied on harvesting Scenedesmus sp. In order to optimize the operating conditions of the electrolytic flocculation process and to quantify the amount of flocculants added, aluminum electrodes were first used in the process. It was found that under optimal conditions, the microalgae removal efficiency using aluminum electrodes could reach $98.5 \%$, while $34.2 \mathrm{mg} \mathrm{L}^{-1}$ of aluminum ions were released during the process. Different metal electrodes were also studied, but high microalgae removal efficiency was witnessed only using aluminum electrodes, indicating the influence of the aluminum ion in flocculation. When non-sacrificial graphite electrodes were used in the electrolytic flocculation process, the corresponding amount of aluminum sulfate was added so that the aluminum ion concentration in water was also equal to $34.2 \mathrm{mg} \mathrm{L}^{-1}$. The result showed that the microalgae removal efficiency of graphite electrodes could reach above $90 \%$ after aluminum sulfate was added. In contrast, using graphite electrodes alone and using the metal salt alone only yielded $22.9 \%$ and $7.1 \%$ of microalgae removal efficiency, respectively. These results indicated that the presence of metal ions is necessary in the electrolytic flocculation process. The energy consumption of the process was found to be $0.3 \mathrm{~kW} \mathrm{~h} \mathrm{~m}$ m $^{-3}$ or $0.88 \mathrm{~kW} \mathrm{~h} \mathrm{~kg}^{-1}$, which is considered to be low energy consumption. The total cost of the process, including energy and

chemicals, was found to be $\$ 0.21 \mathrm{~m}^{-3}$, proving a cost competitive method in microalgae harvesting.
\end{abstract}

Received 1st October 2018

Accepted 10th November 2018

DOI: $10.1039 / \mathrm{c} 8 \mathrm{ra0} 8101 \mathrm{~h}$

rsc.li/rsc-advances

\section{Introduction}

As the demand for energy continues to rise today, more and more researchers are concerned about finding an alternative and sustainable energy form. ${ }^{1}$ Microalgae are well known to be a promising feedstock for biofuels due to their high biomass production, high lipid contents, and low land area requirement. ${ }^{2}$ Another advantage is that large farming of microalgae will not compete with food production. However, the major bottleneck of biofuel production from microalgae is the expensive harvesting process. It has been estimated to be as high as $50 \%$ of the total biofuel production cost. ${ }^{3}$ Therefore, it is necessary to develop an economical and environmentallyfriendly harvesting method for microalgae.

The commonly used microalgae harvesting methods include centrifugation, sedimentation, filtration, flotation, and flocculation. ${ }^{4}$ Among these methods, flocculation is suggested to be

\footnotetext{
${ }^{a}$ Department of Chemical and Biomolecular Engineering, Ohio University, Athens, $\mathrm{OH}$, 45701, USA. E-mail: sl871014@ohio.edu; Tel: +1-740-818-6580

${ }^{b}$ Civil Engineering Department, School of Engineering, The University of Jordan, Amman, Jordan

'Department of Civil Engineering, Ohio University, Athens, $\mathrm{OH}$, USA

${ }^{d}$ Department of Civil \& Environmental Engineering, Old Dominion University, Norfolk, VA, USA
}

a "superior method" due to its high reliability and cost efficiency. ${ }^{5}$ For energy efficient methods such as sedimentation and filtration, flocculation is a key step that determines the success of the harvesting process. Hence, it is necessary to investigate methods that will improve the flocculation and consequently, the removal efficiency by other methods such as sedimentation or filtration. This will be fundamental in optimizing the harvesting process of microalgae. ${ }^{6}$

Inorganic and organic flocculants were usually used to initiate the flocculation process. Inorganic flocculants, such as aluminum sulfate, were widely used in waste water treatment for removing microalgae due to their high effectiveness and low cost. $^{7,8}$ However, one problem of inorganic flocculants was their high dosage requirement, which may be costly and may contaminate the product. ${ }^{9}$ Compared with inorganic flocculants, organic flocculants excelled in their high effectiveness with low dosage requirement. ${ }^{10,11}$ The drawback of organic flocculants, however, includes their high market cost compared to inorganic flocculants, non-biodegradability, and their potential hazards to humans and the environment. ${ }^{12}$

Another method to initiate flocculation is electrolytic flocculation. This type of flocculation can be achieved during the electrolysis process using a metal electrode, usually aluminum. ${ }^{11}$ During the electrolysis, metal electrodes continue to dissolve in water and release metal ions. These ions can 
immediately hydrolyze to form their polymeric ions, which are positively charged in water. Those ions can neutralize the negatively charged microalgae cell surface and destabilize the microalgae suspension, which causes the flocculation of microalgae cells. ${ }^{13}$ Another mechanism for electrolysis caused flocculation is that the negatively charged microalgae cells move toward the anode under the electric field and lose their charge at anode, thereby causing flocculation. ${ }^{5}$

Electrolytic flocculation of microalgae has been reported to be effective by some researchers. Vandamme et al. ${ }^{\mathbf{1 1}}$ studied the effect of electrolytic flocculation on marine and freshwater microalgae using aluminum electrodes. Under the optimal conditions of $\mathrm{pH} 4$ and $150 \mathrm{rpm}$, they found that a current density of $1.5 \mathrm{~mA} \mathrm{~cm} \mathrm{~cm}^{-2}$ and $40 \mathrm{~min}$ of electrolysis could remove $80 \%$ of the microalga Chlorella vulgaris, while a current density of $0.6 \mathrm{~mA} \mathrm{~cm} \mathrm{~cm}^{-2}$ and $20 \mathrm{~min}$ of electrolysis could remove $80 \%$ of the microalga Phaeodactylum tricornutum. The energy consumption of the two processes were 2.1 and $0.2 \mathrm{~kW} \mathrm{~h} \mathrm{~kg}^{-1}$ of microalgae recovered, respectively, which were considered to be low energy consumption rates. Gao et $a l .{ }^{\mathbf{1 4}}$ also showed electrolytic flocculation was effective in harvesting the microalga Microcystis aeruginosa. Under the optimal operating conditions, $100 \%$ microalgae removal was achieved while only $0.4 \mathrm{~kW} \mathrm{~h} \mathrm{~m} \mathrm{~m}^{-3}$ of energy was consumed. However, one of the issues of electrolytic flocculation is the continuous dissolution of metal electrodes. These metal electrodes are considered to be sacrificial electrodes and have to be replaced constantly, which may be costly. Few researchers tried using non-sacrificial electrodes such as carbon electrode as a replacement for metal electrodes. However, since the non-sacrificial electrodes cannot release metal ions in water to form positively charged polymeric ions, the flocculation of microalgae cells merely depends on the charge neutralization at anode, which makes them less effective than metal electrodes. Misra et al. ${ }^{15}$ studied the effect of electrolytic flocculation using carbon electrodes on the microalgae Chlorella sorokiniana and Scenedesmus obliquus. The results showed that microalgae removals of $66 \%$ and $52 \%$ were achieved for Chlorella sorokiniana and Scenedesmus obliquus, respectively, which were much lower than using metal electrodes. The authors overcame the problems by adding a large dosage of $\mathrm{NaCl}\left(6 \mathrm{~g} \mathrm{~L}^{-1}\right)$, which worked as an electrolyte and increased the mass transfer in water. However, adding such amount of electrolyte could also increase the total cost of the process, and prevent the recycle and reuse of microalgae growing media. ${ }^{16}$ On the other hand, the metal ion concentration after the electrolysis process was reported to be much less than adding flocculants, ${ }^{\mathbf{1 1}}$ which indicated the electrolysis process was less harmful to the microalgae biomass and more suitable for recycling medium. It is reasonable to assume that adding the same amount of metal ions during the electrolysis of non-sacrificial electrodes would increase the harvesting effect.

Therefore, in this paper, the electrolytic flocculation using non-sacrificial electrodes was conducted with the addition of metal salt. In order to quantify the amount of metal salt added, a series of electrolytic flocculation experiments using aluminum electrodes was conducted first to optimize the operating conditions including current density, surface area of electrodes submerged in water, distance between electrodes, and stirring speed. After obtaining the optimal conditions, the effect of different metal electrodes was investigated in order to determine the optimal metal ion for the electrolytic flocculation process. These metal electrodes included aluminum, iron, copper, zinc, nickel, and magnesium. After choosing the metal ion, the metal ion concentration in water after the electrolysis process was measured, and the corresponding metal salt was added in the electrolytic flocculation process while using the non-sacrificial graphite electrodes. The result of this process was compared among the electrolytic flocculation using metal electrodes, the electrolytic flocculation using graphite electrodes without the addition of metal salt, and the flocculation caused by adding metal salt only.

\section{Methodology}

\subsection{Microalgae cultivation}

The microalga used in this study was Scenedesmus sp., a freshwater microalga known for its high growth rates and lipid content. ${ }^{17}$ This species was cultivated using diluted anaerobic digestate collected from a commercial anaerobic digester processing agricultural waste and wastewater treatment plant sludge in Columbus, OH. The digestate was diluted and the supernatant was extracted and used as a nutrient medium for the algal growth. The cultivation was done in a $100 \mathrm{~L}$ raceway pond for approximately 14 days, which is the time needed for microalgae to enter stationary phase. After cultivation, $200 \mathrm{~mL}$ of microalgae suspension was collected in a beaker, and was adjusted to different $\mathrm{pH}$ levels for the electrolytic flocculation experiments. The initial dried biomass concentration of microalgae was $(341.9 \pm 7.6) \mathrm{mg} \mathrm{L}^{-1}$.

\subsection{Optimization of current density and initial $\mathrm{pH}$}

Current density not only affects the rate of flocculation, but also determines the energy cost of the electrolytic flocculation process. Initial $\mathrm{pH}$ can also affect the formation of metal hydroxides. To optimize the two parameters, a series of experiments were conducted using aluminum electrodes as the anode and cathode, which was the most commonly used metal in the electrolytic flocculation process. These electrodes were $10.2 \mathrm{~cm}$ long, $1.9 \mathrm{~cm}$ wide and $0.03 \mathrm{~cm}$ thick. A DC power supply Fisher FB300 was used in the electrolysis process to provide different voltages and currents. The microalgae and electrodes were placed in a $250 \mathrm{~mL}$ glass beaker on a stir plate without stirring. The surface area of each electrode submerged in the water was $25 \mathrm{~cm}^{2}$. The distance between the two electrodes was $5.08 \mathrm{~cm}$. The current densities used in these experiments were 1,2 and $4 \mathrm{~mA} \mathrm{~cm}^{-2}$, and the initial $\mathrm{pH}$ of the microalgae suspension were 3, 5, 7 and 9. Every combination of these parameters was tested. The electrolytic flocculation process was conducted under room temperature $\left(25^{\circ} \mathrm{C}\right)$. After 20 min of electrolysis, the DC power was shut off, and the microalgae suspension was left still for 20 min to settle. 
After electrolysis, the microalgae cells tended to aggregate in water, and float to the surface by the gases produced at the electrodes, or settle to the bottom of the beaker under gravity. To measure the microalgae removal efficiency, the microalgae suspension in the middle layer of the liquid was carefully collected without disturbing the aggregated microalgae, and the optical density (OD) was measured using a spectrophotometer at $680 \mathrm{~nm}$. Since it was reported that the OD values have a linear relationship with the microalgae biomass concentration in water, ${ }^{17}$ the microalgae removal efficiency was calculated with initial and final ODs as follows:

$$
\text { Microalgae removal efficiency }=\frac{\left(\mathrm{OD}_{i}-\mathrm{OD}_{f}\right)}{\mathrm{OD}_{i}}
$$

where $\mathrm{OD}_{i}$ is the $\mathrm{OD}$ value of microalgae suspension before the electrolysis, $\mathrm{OD}_{f}$ is the $\mathrm{OD}$ value of the microalgae suspension in the middle layer of the liquid after electrolysis.

The energy consumption per unit volume of microalgae suspension was calculated by the following equation:

$$
W=\frac{U I t}{1000 V}
$$

where $W$ is energy consumption $\left(\mathrm{kW} \mathrm{h} \mathrm{L} \mathrm{L}^{-1}\right), U$ is voltage $(\mathrm{V}), I$ is current (A), $t$ is time (h), $V$ is volume (L).

Hydrogen chloride ( $\mathrm{HCl}$ ) was used to adjust the initial $\mathrm{pH}$, and the cost of $\mathrm{HCl}$ in each process was also calculated. The optimal combination of current density and initial $\mathrm{pH}$ was selected based on the microalgae removal efficiency and the total cost of energy and chemicals.

All of the experiments were conducted in triplicate, and the results reported were the average value of the three readings. Considering the self-flocculating of Scenedesmus sp., control experiments were designed to measure the microalgae removal efficiency after 20 min of sedimentation at different $\mathrm{pH}$ without electrolytic flocculation. To determine the significance of difference between two groups of data, a student's $t$ test with a $95 \%$ confidence interval was conducted.

\subsection{Optimization of other parameters of electrolytic flocculation}

Other parameters that might affect the results of electrolytic flocculation include surface area of electrodes, the distance between electrodes, and stirring speed. In order to choose these parameters, the microalgae removal efficiency and the energy consumption of each electrolytic flocculation process for the different parameters were compared. The surface areas used in the experiments were 16,25 , and $30 \mathrm{~cm}^{2}$. The distance between the two electrodes were $2.54,3.81$, and $5.08 \mathrm{~cm}$. For stirring speed, a magnetic stirrer was used during the electrolysis process, and the stirring speeds used were 0,50 , and $100 \mathrm{rpm}$. The best result from varying a single parameter was used as the experiment condition to conduct the next parameter test, following the order of surface area, distance, and stirring speed. Each condition was tested in triplicate and average results were reported.

\subsection{Investigation of different electrode materials}

The metal materials investigated include aluminum, iron, copper, zinc, magnesium and nickel. These metal electrodes release different metal ions in water to form metal hydroxides. By comparing electrodes made of different materials, the most suitable metal ion for the electrolytic flocculation process can be determined. The operating conditions used in the experiments were obtained from the previous optimization experiments. After choosing the metal materials, the metal ion concentration in water was measured by inductively coupled plasma-optical emission spectrometry (ICP-OES, Thermo Scientific iCAP 6000 series) in order to determine the amount of metal ions released during the electrolytic flocculation process.

\subsection{Electrolytic flocculation using non-sacrificial graphite electrodes}

To investigate the effect of non-sacrificial electrodes on electrolytic flocculation, graphite electrodes were chosen in the experiments. The operating conditions of the electrolytic flocculation process were similar to those in the previous section. Based on the results of the previous section, the corresponding metal salt was chosen as the additive, and was added to the microalgae suspension before the electrolytic flocculation process. The total amount of the metal salt was controlled, so that the metal ion concentration in the water was equal to that obtained from the electrolytic flocculation using the metal electrodes. For comparison, another electrolytic flocculation using graphite electrodes without the addition of the metal salt was conducted. The chemical flocculation using the same amount of metal salt as a flocculant without an electrode was also investigated. For the chemical flocculation, the metal salt was added into the microalgae suspension and mixed sufficiently, and then the microalgae suspension was left still for $20 \mathrm{~min}$ before measuring the OD.

\section{Results}

\subsection{Optimization of current density and initial $\mathrm{pH}$}

The results of electrolytic flocculation using different current densities and initial pH are shown in Fig. 1. Microalgae removal efficiency was similar at $\mathrm{pH} 3$ and 5 under different current densities, so statistically significant difference is shown for those treatments. All other comparisons were significant different. Maximum microalgae removals were achieved at $\mathrm{pH}$ $\leq 5$, with values between $89 \%$ and $95 \%$. Under these $\mathrm{pH}$ conditions, the increase of current density from $1 \mathrm{~mA} \mathrm{~cm}{ }^{-2}$ to 4 $\mathrm{mA} \mathrm{cm}^{-2}$ only showed slight improvement in removal efficiency. At higher $\mathrm{pH}$ values, removal efficiency dropped off markedly. Current density was more important at these higher $\mathrm{pH}$ values, with $4 \mathrm{~mA} \mathrm{~cm}^{-2}$ was much more effective than $1 \mathrm{~mA}$ $\mathrm{cm}^{-2}$. All controls with no electrolysis showed little microalgae removal, showing the self-flocculation of Scenedesmus sp. was insignificant. To calculate the electrical energy consumption of the electrolytic flocculation process, the voltage used of each combination was measured, and, the energy consumption was calculated using eqn (2). Based on the U. S. average cost of 10.41 


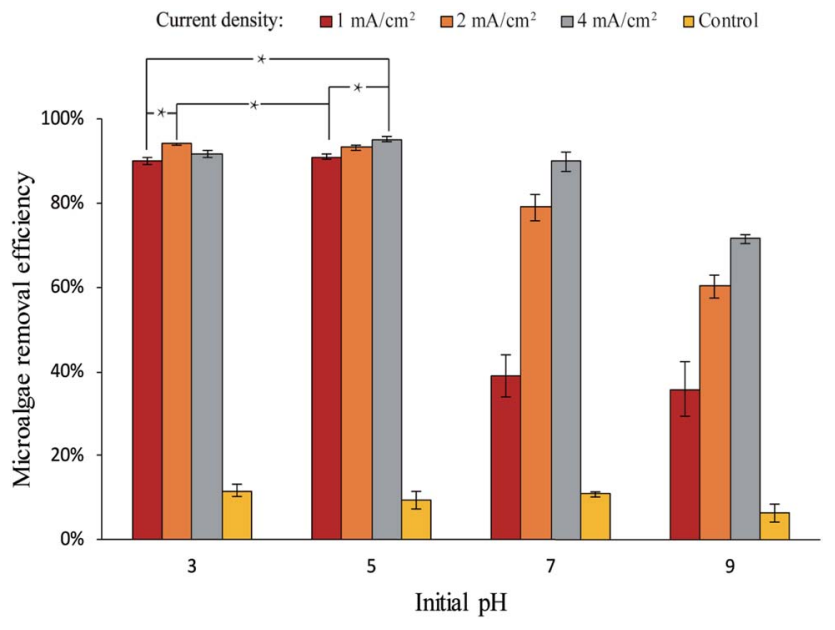

Fig. 1 Effects of the current density and initial pH on the microalga Scenedesmus sp. removal. * denotes significant difference for the $\mathrm{pH}$ $=3$ and $\mathrm{pH}=5$ treatments ( $p<0.05$ with student's $t$-test), all other comparisons were significant.

cents $\mathrm{kW} \mathrm{h}^{-1}$, $^{18}$ the cost of energy was calculated (see Table 1). Under the same current density, the voltage required for the electrolysis increased with the increase of $\mathrm{pH}$, as the voltages

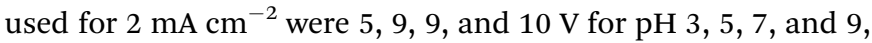
respectively. At lower $\mathrm{pH}$, the resistance of the solution was lower due to the higher ionic strength of the solution.

After the cultivation of microalgae, the $\mathrm{pH}$ of the growing medium was found to be 8.5 , therefore $\mathrm{HCl}$ was required to adjust $\mathrm{pH}$ to acidic conditions. For the chemicals cost of each process, the amount of $\mathrm{HCl}$ used for $\mathrm{pH}$ adjustment was measured and shown in Table 2. According to the price listed on ICIS website, ${ }^{19}$ the cost of $\mathrm{HCl}$ was $\$ 0.215 \mathrm{~kg}^{-1}$. Based on this information, the cost of $\mathrm{HCl}$ was calculated as shown in Table 2. Lower $\mathrm{pH}$ values required higher consumption of $\mathrm{HCl}$, and resulted in higher chemicals cost.

The total cost of each electrolytic flocculation process, which includes the electrical energy cost and the $\mathrm{HCl}$ cost, is shown in Fig. 2. A high current density increased the total energy cost of the process, and a low $\mathrm{pH}$ condition increased the cost of $\mathrm{HCl}$. The selection of current density and $\mathrm{pH}$ should be at a balance
Table 2 The cost of $\mathrm{HCl}$ of the electrolytic flocculation process

\begin{tabular}{lll}
\hline & $\begin{array}{l}\mathrm{HCl} \text { consumption } \\
\left(\mathrm{g} \mathrm{L}^{-1}\right)\end{array}$ & $\mathrm{HCl} \operatorname{cost}\left(\mathrm{S} \mathrm{L}^{-1}\right)$ \\
\hline 3 & 0.3963 & $8.52 \times 10^{-5}$ \\
5 & 0.2607 & $5.61 \times 10^{-5}$ \\
7 & 0.0521 & $1.12 \times 10^{-5}$ \\
9 & 0 & 0
\end{tabular}

between the total cost and the microalgae removal efficiency. Even though costs were lower at higher $\mathrm{pH}$ values as less acid was needed, removal efficiency was much better in the acidic range than in the alkaline range. In addition, good removal efficiencies could be achieved with lower current densities in the acidic trials, greatly decreasing the overall cost. Hence, it is recommended to perform the process in the acidic range with lower current density.

The selection of optimal $\mathrm{pH}$ and current density was based on the results from Fig. 1 and 2. It can be seen from these figures that $2 \mathrm{~mA} \mathrm{~cm}{ }^{-2}$ of current density and $\mathrm{pH} 3$ was a good combination for the electrolytic flocculation process. It resulted in the second highest microalgae removal efficiency, which was $94.0 \% \pm 0.4 \%$. Although the highest microalgae removal was $95.2 \% \pm 0.6 \%$, obtained when using $4 \mathrm{~mA} \mathrm{~cm}^{-2}$ of current density at $\mathrm{pH} 5$, no significant difference was found between these two data $(p=0.19)$. On the other hand, the total cost of the process was much lower at $2 \mathrm{~mA} \mathrm{~cm}{ }^{-2}$ of current density and $\mathrm{pH} 3$, due to less energy consumption. Similarly, the microalgae removal efficiency at $2 \mathrm{~mA} \mathrm{~cm}^{-2}$ and $\mathrm{pH} 5$ was $93.2 \% \pm 0.6 \%$, which was little different from $2 \mathrm{~mA} \mathrm{~cm}^{-2}$ and pH $3(p=0.33)$. However, the total cost of the process when using these parameters was still higher than using $2 \mathrm{~mA} \mathrm{~cm}^{-2}$ and $\mathrm{pH} 3$, as shown in Fig. 2. Therefore, $2 \mathrm{~mA} \mathrm{~cm}^{-2}$ of current density and $\mathrm{pH} 3$ was chosen as the best operating condition tested, when high microalgae removal efficiency was desired. Another good combination was $1 \mathrm{~mA} \mathrm{~cm}{ }^{-2}$ of current density and $\mathrm{pH}$ 5. Lower cost of the process was achieved under these conditions, while the microalgae removal efficiency still reached $91.0 \% \pm 0.7 \%$. For the selection of operating conditions, a high microalgae removal is favored in this research,

Table 1 The electrical energy consumption and cost of the electrolytic flocculation process

\begin{tabular}{|c|c|c|c|c|}
\hline $\mathrm{pH}$ & Current density $\left(\mathrm{mA} \mathrm{cm}{ }^{-2}\right)$ & Voltage used (V) & $\begin{array}{l}\text { Electrical energy } \\
\text { consumption }\left(\mathrm{kW} \mathrm{h} \mathrm{L}{ }^{-1}\right)\end{array}$ & $\begin{array}{l}\text { Electrical energy } \\
\text { cost }\left(\$ \mathrm{~L}^{-1}\right)\end{array}$ \\
\hline 3 & 1 & 3 & $1.30 \times 10^{-4}$ & $1.35 \times 10^{-5}$ \\
\hline 3 & 2 & 5 & $4.23 \times 10^{-4}$ & $4.40 \times 10^{-5}$ \\
\hline 3 & 4 & 11 & $1.87 \times 10^{-3}$ & $1.95 \times 10^{-4}$ \\
\hline 5 & 1 & 5 & $2.16 \times 10^{-4}$ & $2.25 \times 10^{-5}$ \\
\hline 5 & 2 & 9 & $7.64 \times 10^{-4}$ & $7.95 \times 10^{-5}$ \\
\hline 5 & 4 & 12 & $2.03 \times 10^{-3}$ & $2.11 \times 10^{-4}$ \\
\hline 7 & 1 & 5 & $2.16 \times 10^{-4}$ & $2.25 \times 10^{-5}$ \\
\hline 7 & 2 & 9 & $7.64 \times 10^{-4}$ & $7.95 \times 10^{-5}$ \\
\hline 7 & 4 & 13 & $2.21 \times 10^{-3}$ & $2.30 \times 10^{-4}$ \\
\hline 9 & 1 & 5 & $2.16 \times 10^{-4}$ & $2.25 \times 10^{-5}$ \\
\hline 9 & 2 & 10 & $8.50 \times 10^{-4}$ & $8.85 \times 10^{-5}$ \\
\hline 9 & 4 & 16 & $2.55 \times 10^{-3}$ & $2.65 \times 10^{-4}$ \\
\hline
\end{tabular}




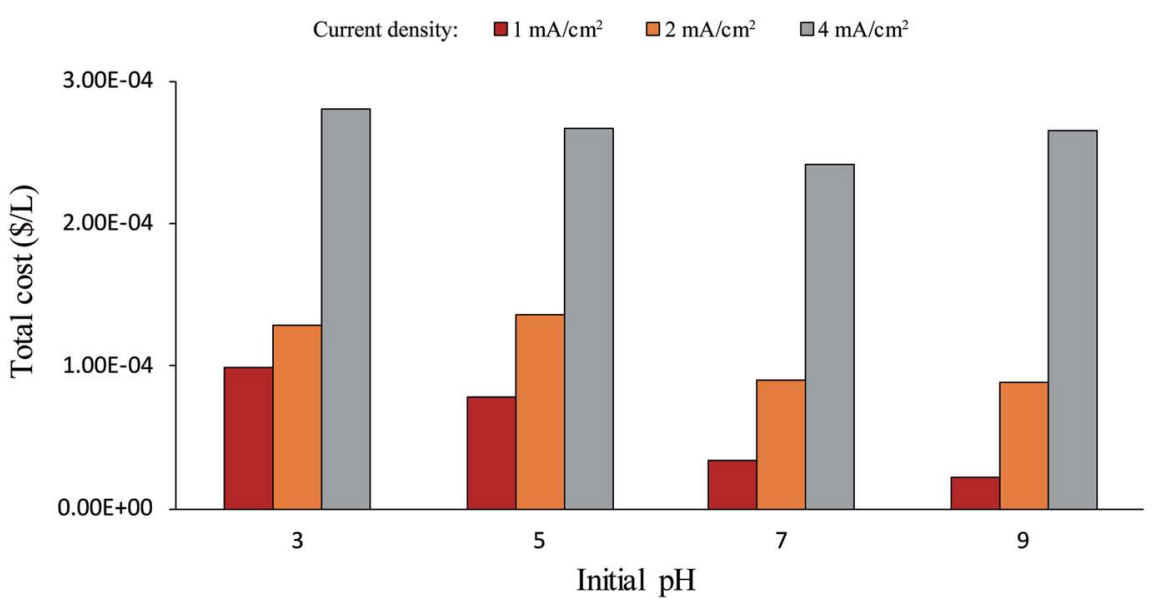

Fig. 2 Total cost of the electrolytic flocculation process under different current densities and initial pH.

therefore $2 \mathrm{~mA} \mathrm{~cm}^{-2}$ of current density and $\mathrm{pH} 3$ was chosen as the optimal operating condition for the electrolytic flocculation process. The disadvantage of using $\mathrm{pH} 3$ is that it increases the difficulty to reuse the solution after the electrolysis, since such acidic condition is not suitable for microalgae cultivation and need to be neutralized before restarting microalgae cultivation. Therefore, $\mathrm{pH} 5$ was preferred if reusing of solution was considered.

\subsection{Effects of other parameters on electrolytic flocculation}

The effect of the electrode surface area on the electrolytic flocculation was presented in Fig. 3a, whereas the effect of the distance between electrodes was shown in Fig. 3b, and the effect of stirring speed was shown in Fig. 3c. The current density and initial pH used in these experiments were $2 \mathrm{~mA} \mathrm{~cm}^{-2}$ and $\mathrm{pH} 3$. The electrode surface area for all the previous experiments (Fig. 1) was $25 \mathrm{~cm}^{2}$. For each experiment, the voltage used was also measured in order to compare the energy consumption under different parameters. The microalgae removal efficiency and voltage used increase with the increase of electrode surface area submerged in water. An increase of surface area from 25 $\mathrm{cm}^{2}$ to $30 \mathrm{~cm}^{2}$ resulted in a statistically significant increase of microalgae removal efficiency from $94.0 \% \pm 0.4 \%$ to $97.7 \% \pm$ $0.8 \%(p=0.031)$. Further increase of the surface area seemed unnecessary, since the microalgae removal efficiency was already above $97 \%$, and increasing the surface area would also increase the energy consumption. Therefore, $30 \mathrm{~cm}^{2}$ of surface area of electrodes was chosen to conduct the following experiments.

The distance between the electrodes and the stirring speed did not have significant effects on microalgae removal efficiency. The distance between the electrodes for all previous experiments (Fig. 1) was $5.08 \mathrm{~cm}$. However, it was observed that reducing the distance between electrodes could reduce the voltage used during electrolytic flocculation process, while increasing the stirring speed could increase the voltage used. Since voltage determines the electrical energy consumption, these operating parameters with lower voltage used are favored. When scaling up, smaller distances between electrodes might increase costs because of the need for more electrodes in a single tank. However, in this study, all tests were conducted on the same volume of solution, so we could not assess this impact. Based on the results from the figures, $30 \mathrm{~cm}^{2}$ of surface area, $2.54 \mathrm{~cm}$ of distance between electrodes, and no stirring were chosen as the optimal conditions. All of the following experiments were conducted under these conditions.

\subsection{Effect of different metal electrodes on electrolytic flocculation}

Fig. 4 shows the electrolytic flocculation results using different metal electrodes. Aluminum was the most suitable metal among the selected metal materials. All other metals were significantly less effective than aluminum for the electrolytic flocculation process. Another finding from these experiments was that voltages used were the same $(3 \mathrm{~V})$ while using different metal electrodes, though the resistivity of these metals was different. Based on these results, aluminum sulfate was chosen as the additive in the following section. The aluminum ion concentration in water after electrolytic flocculation was measured by ICP-OES and was found to be $34.2 \pm 0.5 \mathrm{mg} \mathrm{L}^{-1}$. The result was also in agreement with the calculation using the following equation (Faraday's law):

$$
\left[\mathrm{Al}^{3+}\right]=\frac{I \times t \times M \times 1000}{F \times 3 \times V}=33.6 \mathrm{mg} \mathrm{L}^{-1}
$$

where $I$ is current (A), $t$ is time (s), $M$ is molecular weight of $\mathrm{Al}(\mathrm{g}$ $\left.\mathrm{mol}^{-1}\right), F$ is Faraday constant $\left(\mathrm{s} \mathrm{A} \mathrm{mol}^{-1}\right), V$ is the volume of microalgae suspension (L).

\subsection{Electrolytic flocculation using non-sacrificial graphite electrodes}

The result of electrolytic flocculation using non-sacrificial graphite electrodes is shown in Fig. 5. The harvesting effect of graphite electrodes alone was less effective than aluminum electrodes in the electrolytic flocculation process, since only $22.9 \%$ of microalgae removal was achieved. Similarly, only $7.1 \%$ of microalgae removal was achieved when using aluminum sulfate alone as the flocculant, which was significantly less 
(a)

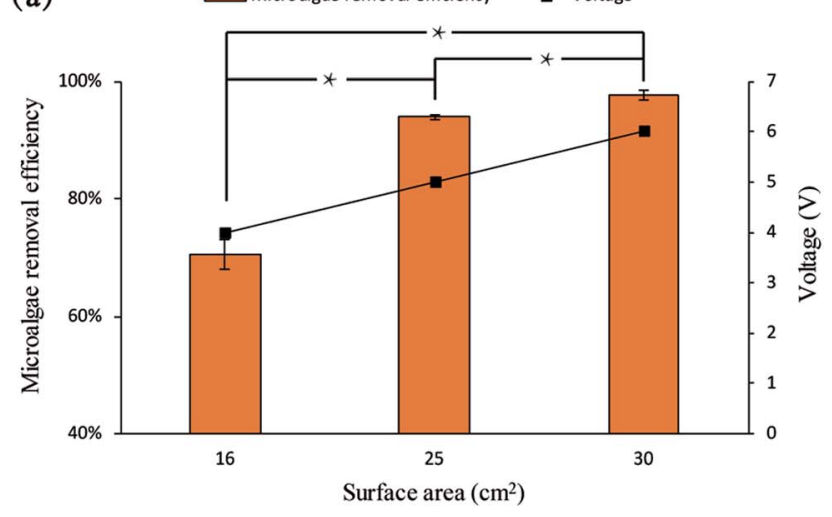

(b)

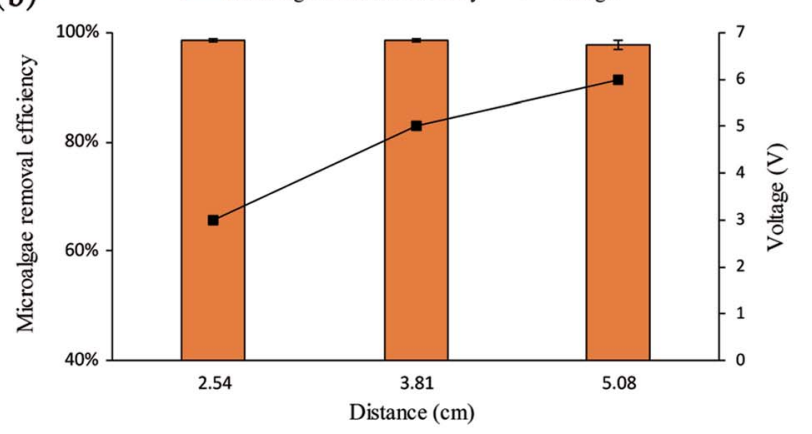

(c)

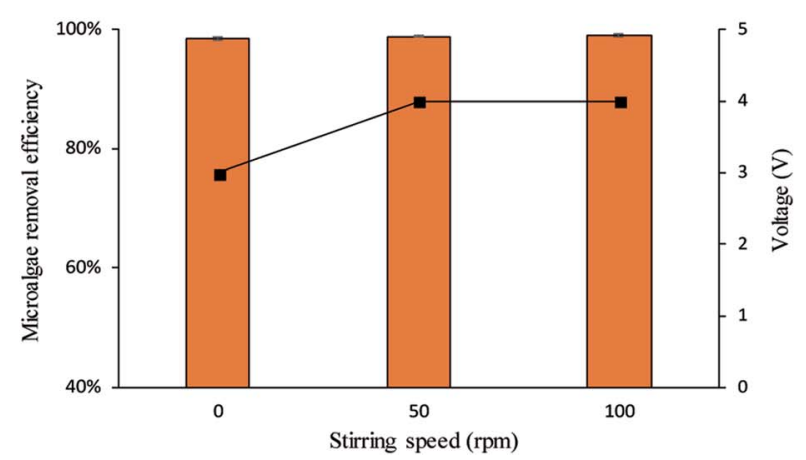

Fig. 3 Effects of electrode surface area (a), distance between electrodes (b), and stirring speed (c) on the electrolytic flocculation process. * denotes significant difference $(p<0.05$ with student's $t$ test).

effective than electrolytic flocculation using aluminum electrodes. However, combining the electrolysis process using graphite electrodes with the addition of aluminum sulfate resulted in a significant increase in microalgae removal efficiency. The microalgae removal efficiency of this method was $92.0 \%$, and was slightly lower than the microalgae removal efficiency of the process using aluminum electrodes (98.5\%), and the difference was statistically significant. The cultivation medium after the electrolysis process was much clearer compared to the medium using graphite electrodes alone or using aluminum sulfate alone (Fig. 5 b).

For comparison, the electrolytic flocculation method was also tested on the microalga Scenedesmus sp. that was cultivated in BG 11 nutrient medium. The result showed that there was

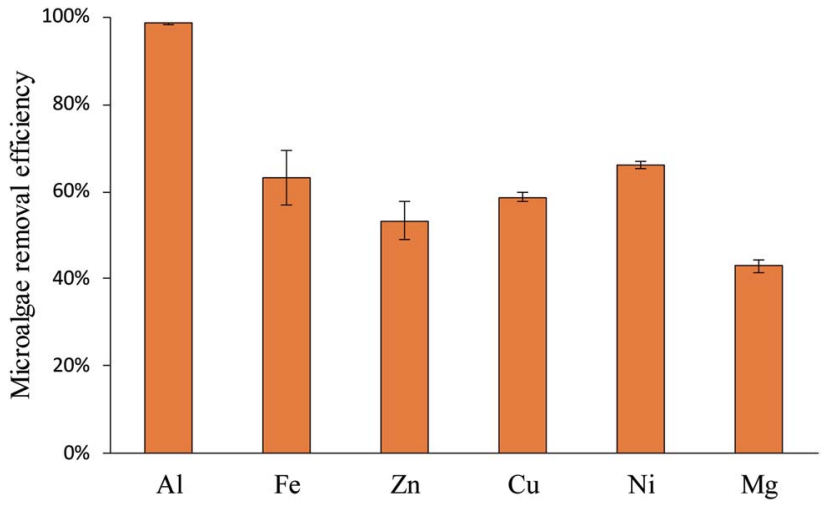

Fig. 4 Comparison of different metal electrodes for electrolytic flocculation.

little difference in the harvesting efficiency of microalgae when the medium changed. In both media, the electrolytic flocculation using graphite electrodes with the addition of aluminum sulfate can reach above $90 \%$ of microalgae removal efficiency. The voltage used in both media was found to be $3 \mathrm{~V}$, and the energy consumption of the process was calculated to be 0.3 $\mathrm{kW} \mathrm{h} \mathrm{m}{ }^{-3}$ of the microalgae solution $\left(0.88 \mathrm{~kW} \mathrm{~h} \mathrm{~kg}^{-1}\right.$ of the microalgae biomass).

\section{Discussion}

The results in Fig. 1 demonstrated the effect of current density and $\mathrm{pH}$ on microalgae removal efficiency using the electrolytic flocculation process. The microalgae removal efficiency increased along with the increase of current density. Increasing the current density provided a stronger electric field, which increased the movement of microalgae cells in water, and resulted in more neutralization of microalgae cells at the anode. In addition, more aluminum ions were released, when the current density increased, which likely caused the destabilization and flocculation of microalgae cells. Acidic condition also results in a higher microalgae removal than alkaline condition. Aluminum ions in acidic conditions can form positively charged aluminum hydroxides, $\mathrm{Al}_{x}(\mathrm{OH})_{y}{ }^{z+}$, which likely neutralized the negatively charged microalgae cells. ${ }^{13}$ However, the aluminum hydroxides can only dominate in water between pH 4.5 to $\mathrm{pH}$ 6, as shown in Fig. $6 .^{20}$ Below pH 4.5, $\mathrm{Al}^{3+}$ dominates in water, while $\mathrm{Al}(\mathrm{OH})_{2}{ }^{+}, \mathrm{AlOH}^{2+}$, and $\mathrm{Al}^{3+}$ become the dominate species at $\mathrm{pH}$ 5. The high microalgae removal efficiency at $\mathrm{pH} 3$ could be caused by $\mathrm{Al}^{3+}$ as well as $\mathrm{AlOH}^{2+}$. During the electrolytic flocculation process, approximately $34 \mathrm{mg} \mathrm{L}^{-1}$ $\left(10^{-3} \mathrm{M}\right)$ of $\mathrm{Al}^{3+}$ was released, and $10^{-5} \mathrm{M}$ of $\mathrm{AlOH}^{2+}$ was formed, based on Fig. 6 . Due to the fact that $\mathrm{Al}^{3+}$ has a high solubility at pH $3\left(2.7 \mathrm{~g} \mathrm{~L}^{-1}\right)$ as shown in Fig. $7,{ }^{21}$ most of aluminum ions at $34 \mathrm{mg} \mathrm{L}^{-1}$ of $\mathrm{Al}^{3+}$ concentration are dissolved. The consistency of the measured $\mathrm{Al}^{3+}$ concentration and the theoretical value also proves this fact. However, at $\mathrm{pH} 5$, aluminum ions could precipitate to form $\mathrm{Al}(\mathrm{OH})_{3}$ due to their lower solubility $(2 \times$ $10^{-7} \mathrm{M}$ for $\mathrm{Al}^{3+}, 10^{-6} \mathrm{M}$ for $\mathrm{Al}(\mathrm{OH})_{2}{ }^{+}$, and $3 \times 10^{-6} \mathrm{M}$ for $\left.\mathrm{AlOH}^{2+}\right) .{ }^{21}$ In consequence, the $\mathrm{Al}(\mathrm{OH})_{3}$ attaches to the microalgae cells and results in the contamination of biomass. On the 


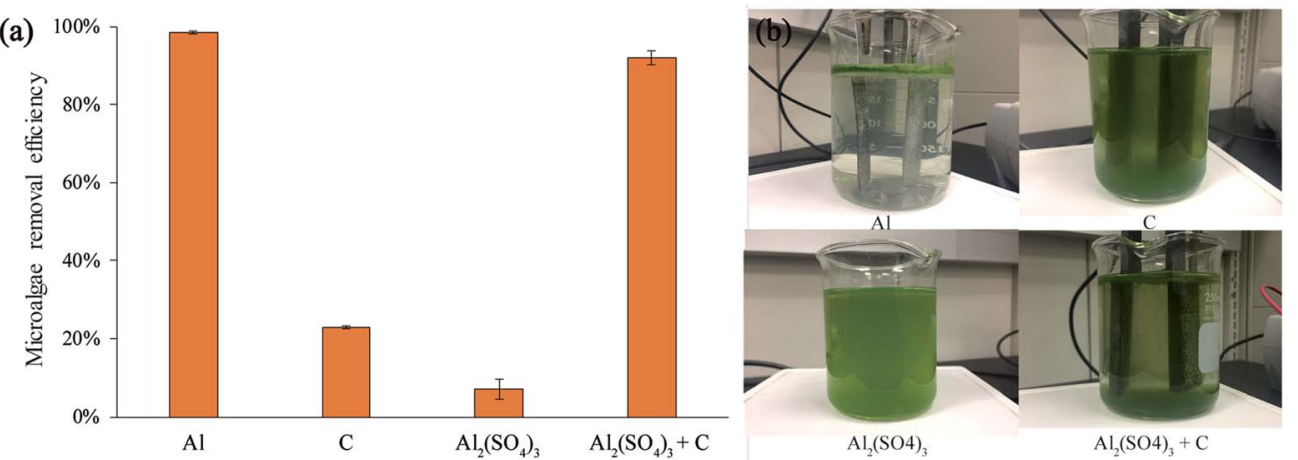

Fig. 5 Comparison of microalgae removal efficiency between flocculation process using aluminum electrodes, graphite electrodes, aluminum sulfate, and graphite electrodes with aluminum sulfate. (a) Microalgae removal efficiency. (b) Clearness of growing medium. The operating conditions were $2 \mathrm{~mA} \mathrm{~cm}^{-2}$ of current density, $\mathrm{pH} 3,30 \mathrm{~cm}^{2}$ of surface area, and $2.54 \mathrm{~cm}$ of distance between electrodes.

other hand, the concentration of $\mathrm{AlOH}^{2+}$ at $\mathrm{pH} 3$ is also higher than at $\mathrm{pH} 5$, although it is not the dominate species. This is due to the higher solubility of $\mathrm{AlOH}^{2+}$ at $\mathrm{pH} 3\left(10^{-2} \mathrm{M}\right)$. As a result, the electrolytic flocculation at $\mathrm{pH} 3$ was favored over it at $\mathrm{pH}$ 5. At alkaline conditions, the negatively charged aluminum hydroxide $\mathrm{Al}(\mathrm{OH})_{4}{ }^{-}$dominates in water, which cannot cause the destabilization of microalgae cells. ${ }^{11}$ Therefore, the microalgae removal efficiency was much lower at alkaline conditions.

Table 1 displayed the energy consumption of the electrolytic flocculation process. Under the same $\mathrm{pH}$, increasing the current density significantly increased the energy consumption. On the other hand, under the same current density, increasing the $\mathrm{pH}$ also increased the energy consumption. This result may be explained by the ion concentration in water. At low $\mathrm{pH}$, there were more hydrogen ions $\left(\mathrm{H}^{+}\right)$in water, which were free charge carriers. The higher their concentration was, the higher

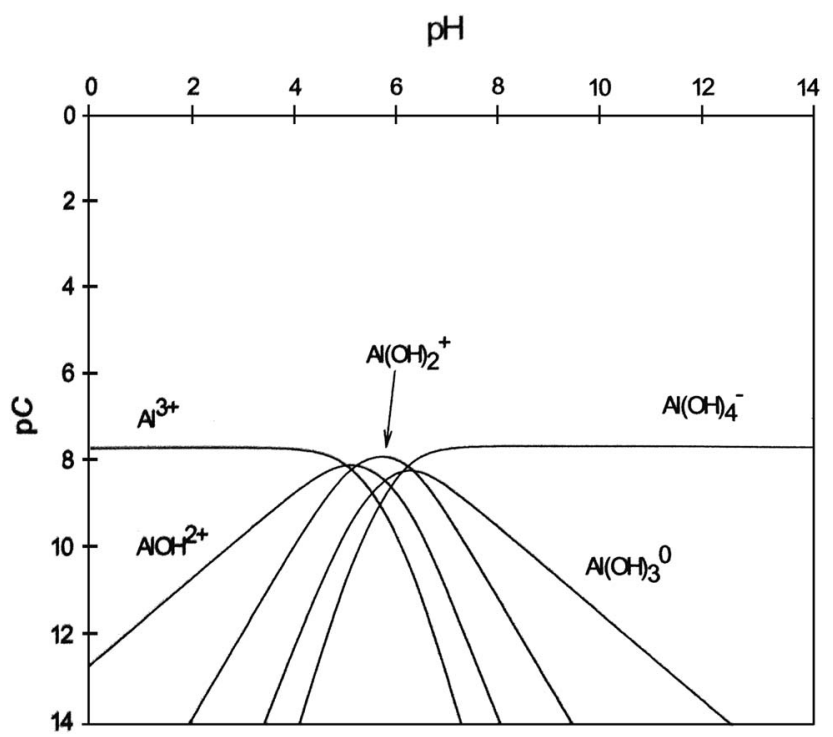

Fig. 6 The $\mathrm{pC}-\mathrm{pH}$ diagram for aluminum, $\mathrm{Al}^{3+}=1.85 \times 10^{-9} \mathrm{M}$. Reprinted from A Problem-Solving Approach to Aquatic Chemistry, J. N. Jensen, p. 317, Copyright (2003), with permission from John Wiley and Sons. ${ }^{20}$ conductivity the solution exhibited..$^{22}$ Therefore, lowering the initial $\mathrm{pH}$ of the microalgae suspension reduced the energy consumption of the process.

Increasing the surface area of electrodes increased the microalgae removal efficiency (Fig. 3a). This result matched the finding by Matos $e t a l^{23}$ The result may be explained by two reasons. Firstly, since the current density was kept as $2 \mathrm{~mA}$ $\mathrm{cm}^{-2}$, the increase of surface area increases the total current used in the system, and therefore promotes the dissolution of aluminum ions. ${ }^{24}$ Secondly, a larger surface area provided more chance for the electrodes to contact with the microalgae cells in water, which could lead to more neutralization of electric charge at the anode.

The distance between electrodes had little effects on microalgae removal efficiency (Fig. 3b). However, reducing the distance between electrodes reduced the voltage used in the electrolytic flocculation process significantly. This was due to

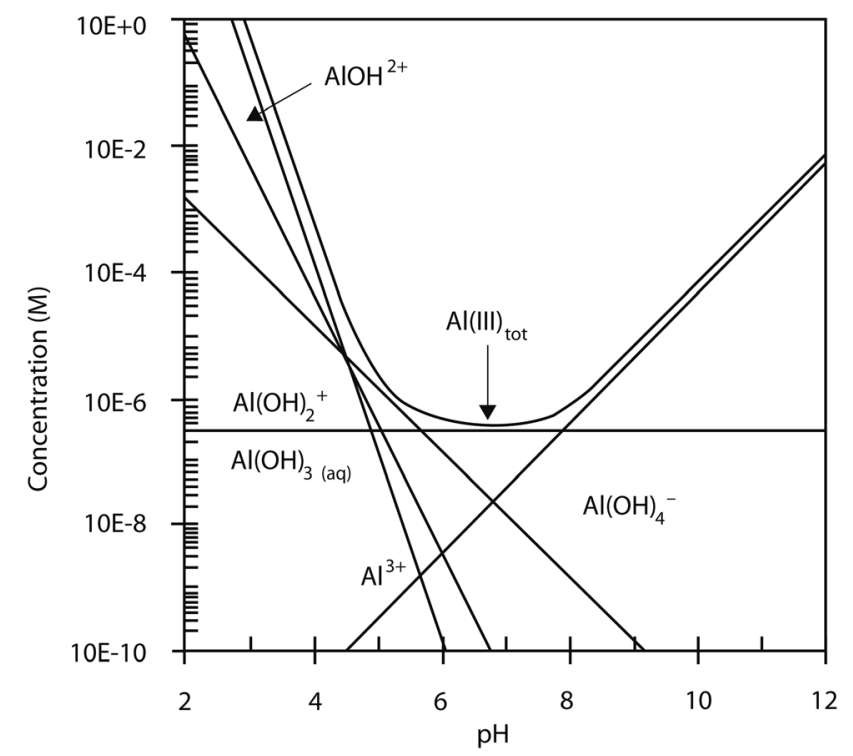

Fig. 7 Solubility of monomeric aluminum. Reprinted from Filtration Separation, vol. 51, no. 4, membrane filtration: managing aluminum in membrane filtration, p. 27, Copyright (2014), with permission from Elsevier. ${ }^{21}$ 
the fact that the distance between the two electrodes could determine the resistance of the system. The resistance can be calculated using the Pouillet's law:

$$
R=\rho \frac{l}{A}
$$

where $R$ is the resistance, $\rho$ is the resistivity, $l$ is length, and $A$ is the cross-section area. In the electrolytic flocculation process, the distance between the electrodes is $l$ in eqn (4), so the voltage used was reduced by half when the distance between the electrodes was halved. To minimize the energy consumption, $2.54 \mathrm{~cm}$ of distance between the electrodes was chosen as the optimal condition.

Fig. $3 c$ shows that there was little difference between the harvesting efficiency at different stirring speeds. Increasing the stirring speed during the process may increase the mass transfer in water, yet due to the fact that a high microalgae removal efficiency was already achieved without stirring, increasing the stirring speed had little effect on the microalgae removal, while increasing the energy consumption. Therefore, no stirring was chosen as the optimal condition.

The effects of different metal electrodes on the electrolytic flocculation process were significantly different (Fig. 4). Because all the metal electrodes were used under the same operating condition, the difference between their harvesting efficiency could only come from the metal ions they released in water. When compared with iron electrodes, aluminum electrodes demonstrate a better microalgae removal efficiency. This result was similar to the finding by Vandamme et al. ${ }^{\mathbf{1 1}}$ and Gao et al. ${ }^{\mathbf{1 4}}$ who showed that the aluminum electrodes were more efficient compared to iron electrodes. To further investigate the reason behind this result, the iron ion concentration in water was measured by atomic absorption spectroscopy after the electrolytic flocculation, and the ferrous ion $\left(\mathrm{Fe}^{2+}\right)$ concentration was determined using the Standard Methods for the Examination of Water and Wastewater (3500-Fe Phenanthroline Method). The result shows the total iron ion concentration was $14.9 \mathrm{mg} \mathrm{L}^{-1}$, containing $8.0 \mathrm{mg} \mathrm{L}^{-1}$ of $\mathrm{Fe}^{2+}$ and $6.9 \mathrm{mg} \mathrm{L}^{-1}$ of $\mathrm{Fe}^{3+}$. The total iron ion concentration was considerably less than aluminum ion concentration $\left(34.2 \mathrm{mg} \mathrm{L}{ }^{-1}\right)$, which explained the low efficiency of iron electrodes. The low concentration of $\mathrm{Fe}^{2+}$ and $\mathrm{Fe}^{3+}$ might be explained by the formation of iron oxides. The ferrous and ferric ions may be oxidized during the electrolysis process and become iron oxides by the following reactions:

$$
\begin{gathered}
\mathrm{Fe}^{2+}+2 \mathrm{Fe}^{3+}+8 \mathrm{OH}^{-} \leftrightarrow \mathrm{Fe}_{3} \mathrm{O}_{4}(\mathrm{~s})+4 \mathrm{H}_{2} \mathrm{O} \\
2 \mathrm{Fe}^{3+}+3 \mathrm{H}_{2} \mathrm{O} \leftrightarrow \mathrm{Fe}_{3} \mathrm{O}_{4}(\mathrm{~s})+6 \mathrm{H}^{+}
\end{gathered}
$$

The formation of these iron oxides may compete with the formation of $\mathrm{Fe}^{3+}$ and $\mathrm{Fe}^{2+}$, which results in the low concentration of total iron ions. The formation of ferric oxide can be confirmed, since a small amount of red/brown solids were observed during the electrolytic flocculation process. In consequence, the $\mathrm{Fe}^{3+}$ concentration in water is much lower than $\mathrm{Al}^{3+}$. Other metal electrodes were also significantly less effective than aluminum electrodes. One possible explanation of the result is the electrical charge of these ions $(2+)$, which is less than the $3+$ charge of $\mathrm{Al}^{3+}$. The higher positive charge of $\mathrm{Al}^{3+}$ might have stronger ability to neutralize the negative charge of microalgae cells, leading to the higher efficiency of aluminum electrodes over other metal electrodes. Another possible explanation is the formation of hydroxides. Although the aluminum hydroxides did not dominate at $\mathrm{pH} 3$, they have a quite large size, and might play a big role in destabilizing the microalgae suspension. However, other metals could not form those hydroxides. The results conflicted with the research conducted by Bleeke et al. ${ }^{25}$ in which the authors stated that magnesium and iron were equally effective as aluminum. The difference of the results may be due to the influence of current density and electrolysis time. Although magnesium and iron are less effective than aluminum, it could still reach a high microalgae removal efficiency at increased current density or after a long time of electrolysis, while the energy consumption is increased dramatically. Based on the results, the effect of aluminum salts as an additive was much better than other metal salts in the electrolytic flocculation process. Therefore, aluminum sulfate as the commonly used flocculant was chosen as the additive in the process. One the other hand, the voltages used for different metal electrodes were the same, indicating the resistivity of metal electrodes had little effect on the electrical energy consumption of the process. This result showed that the primary electrical resistance existed in the microalgae growing media, which determined the electrical energy consumption of the process.

It has been reported that the flocculation mechanism of microalgae was due to the neutralization of the electric charge on the cell surface. In the electrolytic flocculation process, the neutralization could be achieved by two ways: by the positively charged metal ions, and by the positively charged anode..$^{5,11}$ The result in Fig. 5 indicated that a high microalgae removal efficiency cannot be achieved by using $\mathrm{Al}^{3+}$ alone, since it had little flocculation effect on microalgae cells. Similarly, a high microalgae removal efficiency was not achieved by simply using the positively charged carbon anode. However, when both $\mathrm{Al}^{3+}$ and electric field are present in the solution, a high microalgae removal can be achieved. Therefore, both of the mechanisms of the neutralization were necessary for the electrolytic flocculation process to achieve a high microalgae removal efficiency. On the other hand, when only one of those neutralization mechanisms existed, the harvesting efficiency of the electrolytic flocculation was significantly reduced. Therefore, flocculants such as aluminum sulfate should be added in the electrolytic flocculation process when using non-sacrificial electrodes, although it would increase the total cost.

Although aluminum sulfate was commonly used as a flocculant for microalgae removal, it did not work well when used alone in this research. One of the possible reasons was the low dosage of aluminum sulfate used in the research $\left(217 \mathrm{mg} \mathrm{L}^{-1}\right)$. Some researchers reported that high dosages of aluminum sulfate were required to achieve a $90 \%$ microalgae removal, ranging from $1.2 \mathrm{~g} \mathrm{~L}^{-1}$ to $2.5 \mathrm{~g} \mathrm{~L}^{-1} \cdot{ }^{26,27}$ Although the dosage of aluminum sulfate used in this research was significantly lower than the reported dosages, it was still high and may prevent the 
culture medium from being reused. When considering reusing the medium, further optimization of current density, initial $\mathrm{pH}$, and dosage of aluminum sulfate should be conducted in order to minimize the contamination of the solution.

In many of the electrolytic flocculation tests, microalgae were removed from the bulk solution by floating rather than settling. Gas formation at the electrodes resulted in a continuous stream of fine bubbles in the solution which may have a significant effect on algae removal. Unfortunately, we were unable to build an apparatus that could test the impact of this fine bubbling in the absence of bubble measuring device and microbubble generator. To further test the impact of bubbles, the sizes of bubbles generated during the process should be measured, and the microalgae removal efficiency should be tested using microflotation while controlling the size of bubble and the total volume of gas.

The energy consumption of the process $\left(0.3 \mathrm{~kW} \mathrm{~h} \mathrm{~m} \mathrm{~m}^{-3}\right.$ or $0.88 \mathrm{~kW} \mathrm{~h} \mathrm{~kg}^{-1}$ ) can be considered as low energy consumption compared with other harvesting methods reported in the literature. ${ }^{5}$ Another advantage of the process was the application of non-sacrificial electrodes. Unlike sacrificial electrodes such as aluminum, non-sacrificial electrodes do not require periodical replacement. On the other hand, when using aluminum electrodes, one must consider the consumption of the aluminum electrodes in the total cost. Using $65.78 \mathrm{~kW} \mathrm{~h} \mathrm{~kg}^{-1}$ of embodied energy of aluminum ${ }^{28}$ and $34.2 \mathrm{mg} \mathrm{L}^{-1}$ of aluminum consumption (based on the aluminum ion concentration in water), the energy consumption of aluminum electrodes was calculated to be $2.25 \mathrm{~kW} \mathrm{~h} \mathrm{~m}^{-3}$ of the microalgae solution. Based on this information, the total cost of the electrolytic flocculation process using aluminum electrodes was calculated to be $\$ 0.35 \mathrm{~m}^{-3}$ of the microalgae solution. In comparison, the embodied energy of aluminum sulfate was $4.04 \mathrm{~kW} \mathrm{~h} \mathrm{~kg}{ }^{-1}{ }^{29}$ and the total cost of the process using graphite electrodes with aluminum sulfate added was calculated to be $\$ 0.21 \mathrm{~m}^{-3}$. It can be seen from the results that the cost of aluminum sulfate was significantly less than the cost for the replacement of aluminum electrodes. Compared with other harvesting methods, the total cost of the process was much less than centrifugation (\$ 0.53 $\mathrm{m}^{-3}$ ) and flotation with flocculants $\left(\$ 0.47 \mathrm{~m}^{-3}\right) .{ }^{30}$ Therefore, the electrolytic flocculation process was proved to be a competitive method. Furthermore, a study conducted by Salama et al. ${ }^{31}$ demonstrated the high potential of acid mine drainage (AMD) as a flocculant for microalgae harvesting. Because of the high amount of $\mathrm{Fe}^{3+}$ and $\mathrm{Al}^{3+}$ ions in $\mathrm{AMD},{ }^{31}$ it could be used as a replacement for aluminum sulfate and further decease the total cost of the process. Future studies could focus on reducing the amount of chemicals used in the process in order to increase the recyclability of the solution, and investigating the potential of using AMD in the process.

\section{Conclusion}

In this paper, the electrolytic flocculation as a harvesting method for microalgae was studied. The operating conditions of the electrolytic flocculation process were optimized, including the current density, initial $\mathrm{pH}$, surface area of electrodes, distance between electrodes, and stirring speed. Comparing different metal electrodes and their ions, aluminum electrodes and its ions were found to be most effective for the flocculation of microalgae. When using graphite electrodes in the electrolytic flocculation process, it was found that the process could achieve above $90 \%$ of microalgae removal efficiency only if aluminum ions were present in the solution. On the other hand, neither using graphite electrodes alone in electrolytic flocculation process nor using aluminum sulfate alone could achieve a high harvesting efficiency. After an evaluation of energy consumption and total cost, the electrolytic flocculation process was found to be an effective and cost competitive method in microalgae harvesting process.

\section{Conflicts of interest}

The authors declare that they have no conflict of interest.

\section{Acknowledgements}

This work was funded entirely by the National Science Foundation (NSF) through the Sustainable Energy Pathways (SEP) program (Award \# 1230961/1631953).

\section{References}

1 A. S. Japar, M. S. Takriff and N. H. M. Yasin, Harvesting microalgal biomass and lipid extraction for potential biofuel production: A review, J. Environ. Chem. Eng., 2017, 5(1), 555-563.

2 Y. Chisti, Biodiesel from microalgae, Biotechnol. Adv., 2007, 25(3), 294-306.

3 N. Muradov, M. Taha, A. F. Miranda, D. Wrede, K. Kadali, A. Gujar, T. Stevenson, A. S. Ball and A. Mouradov, Fungalassisted algal flocculation: application in wastewater treatment and biofuel production, Biotechnol. Biofuels, 2015, 8(1), 24.

$4 \mathrm{~J}$. J. Milledge and S. Heaven, A review of the harvesting of micro-algae for biofuel production, Rev. Environ. Sci. Bio., 2013, 12(2), 165-178.

5 N. Uduman, Y. Qi, M. K. Danquah, G. M. Forde and A. Hoadley, Dewatering of microalgal cultures: A major bottleneck to algae-based fuels, J. Renewable Sustainable Energy, 2010, 2(1), 12701.

6 A. I. Barros, A. L. Gonçalves, M. Simões and J. C. M. Pires, Harvesting techniques applied to microalgae: A review, Renewable Sustainable Energy Rev., 2015, 41, 1489-1500.

7 M. R. Granados, F. G. Acién, C. Gómez, J. M. FernándezSevilla and E. Molina Grima, Evaluation of flocculants for the recovery of freshwater microalgae, Bioresour. Technol., 2012, 118, 102-110.

8 Y. Shen, W. Yuan, Z. J. Pei, Q. Wu and E. Mao, Microalgae Mass Production Methods, Trans. ASABE, 2009, 52(4), 1275-1287.

9 A. Papazi, P. Makridis and P. Divanach, Harvesting Chlorella minutissima using cell coagulants, J. Appl. Phycol., 2010, 22(3), 349-355. 
10 B. Pushparaj, E. Pelosi, G. Torzillo and R. Materassi, Microbial biomass recovery using a synthetic cationic polymer, Bioresour. Technol., 1993, 43(1), 59-62.

11 D. Vandamme, S. C. V. Pontes, K. Goiris, I. Foubert, L. J. J. Pinoy and K. Muylaert, Evaluation of electrocoagulation-flocculation for harvesting marine and freshwater microalgae, Biotechnol. Bioeng., 2011, 108(10), 2320-2329.

12 C. S. Lee, J. Robinson and M. F. Chong, A review on application of flocculants in wastewater treatment, Process Saf. Environ. Prot., 2014, 92(6), 489-508.

13 M. Mollah, P. Morkovsky, J. Gomes, M. Kesmez, J. Parga and D. Cocke, Fundamentals, present and future perspectives of electrocoagulation, J. Hazard. Mater., 2004, 114(1-3), 199210.

14 S. Gao, J. Yang, J. Tian, F. Ma, G. Tu and M. Du, Electrocoagulation-flotation process for algae removal, J. Hazard. Mater., 2010, 177(1-3), 336-343.

15 R. Misra, A. Guldhe, P. Singh, I. Rawat and F. Bux, Electrochemical harvesting process for microalgae by using nonsacrificial carbon electrode: A sustainable approach for biodiesel production, Chem. Eng. J., 2014, 255, 327-333.

16 E. M. Grima, E. H. Belarbi, F. A. Fernández, A. R. Medina and Y. Chisti, Recovery of microalgal biomass and metabolites: process options and economics, Biotechnol. Adv., 2003, 20(7-8), 491-515.

17 H. A. Abu Hajar, R. G. Riefler and B. J. Stuart, Cultivation of Scenedesmus dimorphus using anaerobic digestate as a nutrient medium, Bioprocess Biosyst. Eng., 2017, 40(8), 1197-1207.

18 The U.S. Energy Information Administration. State Electricity Profiles, The U.S. Energy Information Administration, Available at: https://www.eia.gov/ electricity/state/, Accessed February 9, 2018.

19 ICIS pricing. Hydrochloric Acid. ICIS pricing, Available at: https:/www.icis.com/globalassets/global/icis/pdfs/samplereports/chemicals-hydrochloric-acid.pdf, Accessed February 9, 2018.

20 J. N. Jensen, A Problem-Solving Approach to Aquatic Chemistry, John Wiley \& Sons, Hoboken, NJ, 2003, p. 317.
21 Membrane filtration: Managing aluminum in membrane filtration, Filtr. Sep., 2014, 51(4), 26-28, DOI: 10.1016/ S0015-1882(14)70145-4.

22 S. Creager, Solvent and Supporting Electrolytes, in Handbook of Electrochemistry, ed. C. G. Zoski, Elsevier, 2007, p. 58.

23 C. T. Matos, M. Santos, B. P. Nobre and L. Gouveia, Nannochloropsis sp. biomass recovery by ElectroCoagulation for biodiesel and pigment production, Bioresour. Technol., 2013, 134, 219-226.

24 B. Khaled, B. Wided, H. Béchir, E. Elimame, L. Mouna and T. Zied, Investigation of electrocoagulation reactor design parameters effect on the removal of cadmium from synthetic and phosphate industrial wastewater, Arabian J. Chem., 2015, DOI: 10.1016/j.arabjc.2014.12.012, http:// linkinghub.elsevier.com/retrieve/pii/S1878535214003621.

25 F. Bleeke, G. Quante, D. Winckelmann and G. Klöck, Effect of voltage and electrode material on electroflocculation of Scenedesmus acuminatus, Bioresour. Bioprocess, 2015, 2(1), http://www.bioresourcesbioprocessing.com/content/2/1/36.

$26 \mathrm{H}$. Kwon, M. Lu, E. Y. Lee and J. Lee, Harvesting of microalgae using flocculation combined with dissolved air flotation, Biotechnol. Bioprocess Eng., 2014, 19(1), 143-149.

27 L. Zhu, Z. Li and E. Hiltunen, Microalgae Chlorella vulgaris biomass harvesting by natural flocculant: effects on biomass sedimentation, spent medium recycling and lipid extraction, Biotechnol. Biofuels, 2018, 11, 183.

28 B. V. Venkatarama Reddy and K. S. Jagadish, Embodied energy of common and alternative building materials and technologies, Energ. Buildings, 2003, 35(2), 129-137.

29 C. Maas, Greenhouse Gas and Energy Co-Benefits of Water Conservation, Canadian Water and Wastewater Association, 2009.

30 E. Poelman, N. De Pauw and B. Jeurissen, Potential of electrolytic flocculation for recovery of micro-algae, Resour., Conserv. Recycl., 1997, 19(1), 1-10.

31 E.-S. Salama, B.-H. Jeon, M. B. Kurade, R. A. I. Abou-Shanab, S. P. Govindwar, S.-H. Lee, I.-S. Yang and D. S. Lee, Harvesting of freshwater microalgae Scenedesmus obliquus and Chlorella vulgaris using acid mine drainage as a cost effective flocculant for biofuel production, Energy Convers. Manage., 2016, 121, 105-112. 